\section{A biologia molecular contribuindo para a compreensão e a preven ção das doenças hereditárias}

\author{
Molecular biology contribution \\ to the understanding and prevention \\ of genetic disorders
}

M ayana Zatz 1

\footnotetext{
1 Departamento de Biologia, Instituto de Biociências, U niversidade de São Paulo (IBUSP). Rua do M atão, 277 , Cidade Universitária, 05508-900, São Paulo SP. mayazatz@usp.br
}

\begin{abstract}
The sequencing of the human genome raised many questions such as: H ow the human genome project will influence our lives? How the medicine will ben efit from the study of genes? What are the application in practice and what can we expect from the future? What are the ethical implications? This chapter illustrates how genetic diseases, such as neuromuscular disorders are contributing to our understanding of the human genome. It helps us to start to understand how our genes work and why they cause diseases when mutated. O ne of the practical application of studying genes is the improvement of molecular diagnosis for a growing number of disorders which is of utmost importance to avoid other invasive exams, identify "at risk" couples and prevent the birth of new cases (through genetic counseling and prenatal diagnosis). Potential new treatments for neuromuscular and other genetic disorders including therapeutic cloning, the use of stem cells and the ethical implication of genetic tests are also discussed. The benefit of each test, in particular for disorders of late onset for which there is still no treatment have to be exhaustively discussed with the consulents before their application

Key words H uman genome, M olecular diagnosis, N euromuscular disorders, Therapeutic cloning, Stem cells, Ethical issues
\end{abstract}

Resumo 0 fim do seqüenciamento do genoma humano levanta inúmeras questões: Como o projeto genoma humano vai influenciar nossas vidas? Como a medicina tem se beneficiado do estudo dos genes? Q uais são as aplicações práticas imediatas e o que se espera para 0 futuro? Quais são as implicações éticas? Este capítulo ilustra como as doenças genéticas têm contribuído para a compreensão do genoma humano. Ajuda-nos a entender como nossos genes funcionam quando normais e por que causam doenças quando alterados. Do ponto de vista prático, o estudo dos genes tem permitido o diagnóstico molecular para um número crescente de patologias, o que é fundamental para evitar outros exames invasi vos, identificar casais em risco, e prevenir o nascimento de novos afetados. Além disso, discute-se quais são as perspectivas futuras em relação ao tratamento destas e de outras patologias genéti cas incluindo a clonagem para fins terapêuticos e a utilização de células-tronco. Finalmente aborda as implicações éticas relacionadas ao uso de testes genéticos. O s benefícios de cada teste, principalmente para doenças de início tardio para as quais ainda não há tratamento, têm que ser discutidos exaustivamente com os consulentes antes de sua aplicação. Palavras-chave Genoma humano, Diagnóstico molecular, Doenças neuromusculares, Clonagem terapêutica, Células-tronco, Aspectos éticos 


\section{Introdução}

0 grande acontecimento do ano 2001 foi, sem dúvida, 0 anúncio de que o sequenciamento do Genoma H umano está quase completo. A mídia não se cansou de repetir que os conhecimentos gerados irão revolucionar a medicina. Entretanto, fala-se muito pouco a respeito das aplicações imediatas deste grande feito científico. Como o projeto Genoma H umano vai influenciar nossas vidas? Como a medicina tem se beneficiado do estudo dos genes? 0 que existe de prático e o que se espera para o futuro? Quais são as implicações éticas?

$N$ a realidade, 0 anúncio do sequenciamento do genoma humano ainda não trouxe respostas para questões fundamentais como: Q uantos genes temos na realidade? Será que são realmente 30.000 , ou mais? Quantas proteínas são codificadas por estes genes? Como os genes interagem entre si e com o ambiente? Quanto os nossos genes determinam a nossa personalidade e o nosso comportamento? Cada questão respondida abre um leque de novas questões, inclusive do ponto de vista ético, como veremos a seguir com o exemplo das doenças neuromusculares. Ainda estamos na ponta do iceberg, mas a aventura promete ser fascinante.

Por outro lado, a biologia molecular tem contribuído de maneira significativa para a compreensão de como nossos genes funcionam, quando normais e por que causam doenças quando alterados. Além disso, o diagnóstico molecular para um número crescente de patologia tem sido fantástico para evitar outros exames invasivos, identificar casais em risco e prevenir o nascimento de novos afetados (a partir do aconselhamento genético e do diagnóstico pré-natal). Entender como nossos genes funcionam é o primeiro passo para o tratamento dessas patologias. $M$ as enquanto buscamos a preven ção e obviamente a cura, temos também um compromisso ético em relação ao uso de testes genéticos que devem ser discutidos com os consulentes antes de serem realizados.

\section{As distrofias musculares progressivas}

As distrofias musculares progressivas constituem um grupo de doenças, caracterizadas por uma degeneração progressiva e irreversível da musculatura esquelética, e que tem sido objeto de muitas pesquisas. Já foram mapeados genes responsáveis por mais de 30 formas de distrofia, cuja herança pode ser autossômica dominante, autossômica recessiva e ligada ao $\mathrm{X}$. Além disso, sabe-se que existem formas ainda não identificadas. Os avanços da biologia molecular na última década revolucionaram nossos conhecimentos e começam a responder perguntas fundamentais tais como: Qual é o defeito básico? 0 que leva os músculos a degenerar? Como explicar a heterogeneidade genética, isto é, como mutações em genes diferentes podem resultar em um mesmo fenótipo? $\mathrm{Ou}$, ao contrário, como mutações em um mesmo gene podem levar a quadros clínicos diferentes? Por outro lado, a análise molecular levantou outras questões intrigantes. Por exemplo, tem-se observado em um número crescente de doenças que pacientes com a mesma mutação podem ter quadros clínicos totalmente diferentes (M cN ally et al., 1996; Passos-Bueno et al., 1999) ou que alguns genes autossômicos afetam mais um sexo do que o outro (I keuchi et al., 1996; Iughetti et al., 1996; Zatz et al., 1997; 1998). A explicação para estas observações, al ém de fascinante, será extremamente importante para futuros tratamentos.

\section{As distrofias de D uchenne e Becker}

Dentre as diferentes miopatias, a distrofia de Duchenne (DM D) de herança recessiva ligada ao cromossomo $X$ é a mais comum, com uma incidência de 1 em cada 3.000 nascimentos de sexo masculino (Emery, 1993). Já a distrofia tipo Becker (DM B), alélica à DM D (isto é, localizada no mesmo loco que a DM D), é cerca de 10 vezes mais rara. A diferença entre essas duas formas está na idade de início e velocidade de progressão. $\mathrm{Na} D M \mathrm{D}$, os sinais clínicos iniciam-se entre 3-5 anos de idade (com quedas freqüentes, dificuldades para subir escadas, correr e levantar do chão), o confinamento à cadeira de rodas se dá até os 12 anos de idadee os afetados raramente sobrevivem após a terceira década. Já na D M B, os sintomas iniciamse em geral na segunda década, os afetados sempre andam após os 16 anos e a velocidade de progressão é extremamente variável. Cerca de $30-50 \%$ dos pacientes com DM D têm retardo mental cujas causam ainda estão sendo investigadas (Rapaport, 1991; Rapaport et al., 1992).

Pacientes com DMD e DM B têm um aumento significante (até 2.000 vezes os valores 
normais) da enzima creatino-quinase (CK) no soro sanguíneo que é liberada do músculo distrófico, mesmo antes do aparecimento dos sinais clínicos (Zatz et al., 1976; 2001). Entretanto, atéa década de 1980 , não se tinha idéia acerca do mecanismo molecular que causava estas distrofias e nem se a forma grave de Duchenne e a variante mais leve de Becker eram causadas por um único gene ou dois independentes.

A pós a localização do gene da DM D/DM B no braço curto do cromossomo X, em 1981, do qual nosso grupo participou (Zatz et al., 1981), descobriu-se em 1984, que os genes da DM D e DM B eram alelos, isto é ocupavam o mesmo loco no cromossomo X. M as foi só após a clonagem do gene DM D/DM B em 1987 (Koenig et al., 1987; 1989) que o produto gênico foi identificado: uma proteína do citoesqueleto da membrana, que foi denominada distrofina (Hoffman et al., 1987; 1988), e cuja função mais provável seria o de manter a estabilidade da membrana da célula muscular.

$\mathrm{H}$ oje sabe-se que as mutações que causam DMD ou DM B são deleções no gene da distrofina em cerca de $60 \%$ dos casos, duplicações em 5-6\% dos casos e mutações de ponto (em uma única base ou nucleotídeo do DNA) nos casos restantes (Koenig et al., 1989; Lindlöf et al., 1989). A diferença entre a DM D ea DM B depende da manutenção ou não do quadro de leitura do RNA mensageiro (RNAm). $\mathrm{Na}$ $D M B$, a deleção é em fase, isto é, o quadro de leitura do RNAm é mantido e tem-se como resultado uma proteína quantitativamente reduzida ou deletada internamente, mas em parte funcional. Já na DM D, a deleção é fora de fase, isto é, o quadro de leitura do RNAm não é mantido, tem-se uma proteína severamente truncada e que é rapidamente destruída pela célula (M onaco et al., 1988).

0 estudo de mais de 1.000 pacientes com DMD/DMB em nosso laboratório (Takata, 1995) mostrou que cerca de $60 \%$ dentre eles (tanto os casos de DM D como de DM B) têm deleções no gene da distrofina. Além da manutenção do quadro de leitura do RN Am, o sítio da deleção é muito importante na determinação da severidade do quadro clínico. Por exemplo, deleções nas regiões de ligação da distrofina a outras proteínas (regiões $C$ terminal e $\mathrm{N}$-terminal) resultam na maioria dos casos em quadro mais grave (Vainzof et al., 1990; 1993a; 1993b). A região C terminal, em particular, é fundamental porque constitui o ponto de ligação da distrofina com glicoproteínas as- sociadas à membrana, e, portanto, deleções nessa região levam quase sempre a um quadro grave de DMD. Por outro lado, deleções de até $50 \%$ do gene podem estar associadas a um quadro benigno desde que estejam restritas à região central do gene (Passos-Bueno et al., 1994). 0 quadro leve explica-se porque se a deleção está restrita ao domínio em bastão da distrofina, mesmo que se tenha um encurtamento dessa proteína, os sítios de ligação não ficam alterados, permitindo uma função parcial. Este estudo de correlação genótipo:fenótipo dentro do gene da distrofina e a caracterização da função de cada domínio da proteína tem sido fundamental para futuras tentativas em terapia gê nica, utilizando-se minigenes funcionais.

\section{Aspectos genéticos}

Cerca de $1 / 3$ dos casos de DM D são causados por mutações novas (Zatz et al., 1977), e os restantes $2 / 3$ são herdados de mães portadoras. A maioria (mais de $90 \%$ ) das mulheres portadoras de mutações no gene da distrofina é assintomática (Emery, 1993). Entretanto tem um risco de $50 \%$ de passar o gene defeituoso para a sua descendência, isto é, metade dos filhos pode ser afetada e metade das filhas portadoras, porém clinicamente normais. Outro aspecto importante (observado por nosso grupo e pesquisadores da H olanda) é o mosaicismo gonadal. I sto é, aproximadamente $10 \%$ das mães de casos isolados de DM D, nas quais não foi detectada mutação no sangue periférico, podem ser portadoras da mutação na linhagem germinativa (Passos-Bueno et al., 1990; 1992). Estas mulheres têm um risco aumentado de vir a ter filhos afetados pela DM D.

\section{D iagnóstico e aconselhamento genético}

\section{Diagnóstico}

O exame de DNA em sangue periférico (ou em raspado de mucosa bucal) tem sido muito importante para o diagnóstico, evitando, em muitos casos, a realização de exames invasivos como a biopsia muscular ou a eletroneuromiografia (que além de ser um exame doloroso não auxilia no diagnóstico diferencial entre as várias formas de distrofias). Do ponto de vista prático, em casos suspeitos os passos a serem seguidos para o diagnóstico são os seguintes: 
1) Dosagem de CK no soro: se aumentado sugere o diagnóstico de distrofia muscular (Zatz et al.,1976).

2) Análise de DN A: pesquisa de deleção no gene da distrofina; se for encontrada deleção confirma-se o diagnóstico de DMD/DM B.

3) Biopsia muscular: é indicada se não for encontrada deleção no gene da distrofina, se não houver história familiar de herança recessiva ligada ao cromossomo $X$ ou em crianças que são casos isolados, nas fases iniciais, para um diagnóstico diferencial entre DM D eDM B. A primeira proteína a ser pesquisada é a distrofina, pela técnica de imunofluorescência e western blot (Vainzof et al., 1990; 1993a). Os possíveis resultados são:

a) distrofina ausente: confirma-se o diagnóstico de distrofia de Duchenne;

b) distrofina quantitativamente diminuída ou com peso molecular diminuído (através de análise por western blot): o diagnóstico de distrofia tipo Becker é o mais provável;

c) distrofina normal: pode tratar-se de distrofia tipo cinturas ou outra forma de distrofia muscular. 0 passo seguinte é analisar as diferentes proteínas associadas às formas autossômicas recessivas tais como as sarcoglicanas, a calpaina-3, a disferlina, a teletonina em biopsia muscular (Anderson et al., 1998; 1999; Spencer et al., 1997; Vainzof et al., 1996).

\section{Estimativas de riscos genéticos}

Para identificação de portadoras e estimativas de riscos genéticos os passos a serem seguidos são:

1) 0 paciente é caso isolado e tem deleção no gene da distrofina

a) Se a mãe (e/ou irmã do afetado) for portadora da deleção confirma-se que é ( são) heterozigota(s). N este caso há risco de $50 \%$ de vir a ter filhos afetados e filhas portadoras. É possível realizar diagnóstico pré-natal de certeza através da análise de DNA extraído de vilosidades coriônicas, ao redor de 10 semanas de gestação.

b) Se a mãe não tiver deleção em sangue periférico existe ainda um risco de mosaicismo gonadal que varia de acordo com o sítio da deleção (Passos-Bueno et al., 1992). Se for no início do gene, o risco para um feto de sexo masculino é de cerca de 15\%; se for na região central do gene, o risco para um feto de sexo masculino é de cerca de $2 \%$.

c) Se uma irmã de afetado não tiver deleção em sangue periférico, o risco de que seja portadora é desprezível.

2) 0 paciente é caso isolado e não tem deleção no gene da distrofina

$N$ estes casos compara-se o cromossomo $X$ (através de marcadores polimórficos de DNA ao longo do gene da distrofina) do afetado com outros indivíduos da geneal ogia. As pessoas a serem analisadas e a estimativa de risco genético dependem da estrutura da família.

3) Existe história familiar compatível com herança ligada ao $X$

$N$ esta situação todas as mães de afetados são portadoras certas do gene (risco de $50 \%$ para descendentes de sexo masculino) e todas as irmãs têm risco de $50 \%$ de serem portadoras (Zatz et al., 1989). 0 exame de DNA a ser realizado vai depender da presença ou não de deleção no afetado.

\section{Distrofias tipo cinturas}

As distrofias tipo cinturas ("limb-girdle muscular dystrophies") constituem um grupo heterogêneo de doenças caracterizadas por uma fraqueza proximal das cinturas dos membros (cintura pélvica e escapular) e do tronco, sem comprometimento dos músculos faciais ou da inteligência. Já foram identificados 15 genes responsáveis por este quadro clínico, seis com herança autossômica dominante e nove com herança autossômica recessiva (Bushby, 1999; Moreira et al., 1997; N euromuscular Disorders, 2000; Weiler et al., 1998). É um exemplo de heterogeneidade genética não-alélica, isto é, genes diferentes resultando em um fenótipo semelhante. As formas dominantes são relativamente raras e constituem menos de $10 \%$ dos casos (Bushby, 1999; Passos-Bueno et al., 1999; Zatz et al., 2000).

Dentre as formas recessivas, distingue-se um subgrupo, as sarcoglicanopatias, normalmente associadas a um quadro clínico, em geral, mais severo, semelhante à forma Duchenne. Por este motivo, estas formas também são classificadas como "Duchenne-like" (Azibi et al., 1993; Passos-Bueno et al., 1999). Existem quatro formas de sarcoglicanopatias, causadas por mutações nos genes que codificam quatro glicoproteinas associadas a distrofina formando o complexo distrofina-glicoproteinas associadas. São elas: a LGM D2C que codifica a $\gamma$ sarcoglicana, a LGM D2D, que codifica a $\alpha$-sarcoglicana, a LGM D2E que codifica a $\beta$-sarco- 
glicana e a LGM D2F que codifica a $\delta$ sarcoglicana (Azibi et al., 1993; Ben Othmane et al., 1992; Bonnemann et al., 1995; Lim et al., 1995; M cN ally et al., 1996; Nigro et al., 1996; PassosBueno et al., 1995; 1996; Roberds et al., 1994). Como estas quatro proteínas estão interligadas (Ervasti \& Campbell, 1991; Vainzof et al., 1996; 1999b) uma mutação que cause ausência de qualquer uma das sarcoglicanas provoca uma desagregação de todo o complexo, resultando geralmente em um quadro severo de distrofia. Esta observação explica como mutações em genes diferentes podem causar um mesmo quadro clínico.

Com exceção da forma LGMD2D, cujo quadro clínico é muito variável as outras três sarcoglicanopatias geral mente mostram uma evolução rápida, e os pacientes dificilmente conseguem andar após os 16 anos de idade (M oreira et al., 1998; Passos-Bueno et al., 1995 1996; Zatz et al., 2000). Entretanto, existem exceções e já foram identificados pacientes com um quadro mais benigno pertencentes a qualquer uma das sarcoglicanopatias. A enzima CK também se apresenta muito el evada no soro, principalmente nas fases iniciais. A maioria dos pacientes tem hipertrofia de panturrilhas quando na fase ambulatória. Q uando o paciente é do sexo masculino e não existe história familiar o diagnóstico clínico é indistinguível da forma Duchenne ligada ao cromossomo X. Por outro lado, em meninas afetadas, que são casos isolados, deve excluir-se uma distrofinopatia. Em todos esses casos, a confirmação do diagnóstico depende da análise das proteínas distrofina e sarcoglicanas em biopsia muscular e da análise de DNA.

$\mathrm{N}$ as distrofias tipo cinturas não-sarcoglicanas, o quadro clínico geralmente é mais benigno e a maioria dos afetados consegue deambular após os 16 anos (Passos-Bueno et al., 1996; Zatz et al., 2000) embora o quadro também seja muito variável. As formas já mapeadas são:

1) LGM D 2A, no braço longo do cromossomo 15 (Beckmann et al., 1991), que codifica a enzima cal paina-3, também denominada calpainopatia (CAPN3). A maioria dos pacientes tem hipertrofia de panturrilhas e consegue andar nas pontas dos pés, mas não nos calcanhares nas fases iniciais do processo. A enzima sé rica CK apresenta um aumento médio de 19 vezes, variando entre 2 e 93 (Zatz et al., 2001).

As cal painas são proteases e a forma específica do músculo, a calpaina-3, é uma protease ativada pelo cálcio (Richard et al., 1995; Spen- cer et al., 1997; Baghdiguian et al., 1999). Dentre as distrofias de cinturas de herança $A R, a$ LGM D2A é a única forma descrita até o momento cujo produto gênico é uma proteína com propriedades enzimáticas e não uma proteína estrutural. A função da cal paina- 3 ainda não está completamente esclarecida, mas trabalhos recentes sugerem que ela poderia estar associada a uma cadeia de eventos levando à apoptose. 0 gene da cal paina tem 24 exons ( $r e$ giões codificadoras do DNA, isto é, que são traduzidas em proteínas) e até o presente já foram descritas cerca de 100 mutações patogênicas que causam a LGMD2A (Richard et al., 1999). A maioria delas (70\%) são únicas em cada família, o que torna extremamente difícil o diagnóstico desta forma de distrofia a partir do estudo molecular, em casos isolados. Entretanto, a análise molecular de pacientes brasileiros realizada no nosso laboratório (dados ainda não publicados) tem mostrado que existem mutações recorrentes equea análise de 5 exons permite confirmar o diagnóstico em mais de $70 \%$ dos casos (De Paula e col., manuscrito em preparação). Além da importância prática, 0 estudo da origem das mutações para diferentes doenças genéticas tem sido muito importante em genética de populações. Além disso, a possibilidade recente de se estudar a expressão da cal paina- 3 em biopsia muscular tem sido valiosa para confirmação clínica e estudos de correlações genótipo:fenótipo. Estudos realizados em nossos pacientes ( $M$ ariz Vainzof, comunicação pessoal) mostraram que a cal paina encontra-se totalmente deficiente em cerca de $70 \%$ dos pacientes com LGM D $2 A$ e parcialmente deficiente nos outros $30 \%$. Entretanto, um fato intrigante, é que embora haja uma correlação entre tipo de mutação, presença ou não da proteína cal paina e gravidade do quadro clínico há sempre exceções. Isto indica claramente a existência de outros fatores que modificam a ação primária dos genes.

2) LGM D2B, em $2 p$ (no braço curto do cromossomo 2), codifica a proteína disferlina, é também classificada como disferlinopatia (DYSF) (Bashir et al., 1998; Liu et al., 1998; Anderson et al., 1999). Clinicamente, esta forma de distrofia é em geral mais benigna, mas também apresenta grande variabilidade inter e intrafamilial. A hipertrofia de panturrilhas é rara nesta forma de distrofia e observa-se comumente uma atrofia distal. U ma observação interessante é que freqüentemente os pacientes perdem a capacidade para andar nas pontas 
dos pés antes de perder a capacidade para andar nos calcanhares. Os níveis séricos da enzima CK podem estar muito elevados (em média 36 vezes acima do normal, variando entre 3 e 211 vezes) principalmente nos estágios iniciais (Zatz et al., 2000; 2001).

A função da proteína disferlina na patologia da distrofia tipo 2B permanece desconhecida. No músculo esquelético humano a disferlina localiza-se na membrana da fibra muscular e mostrou-se deficiente em pacientes afetados por esta forma de distrofia. 0 gene da disferlina é muito grande (tem cerca de 55 exons) 0 que torna, do mesmo modo que na LGM D2A, o diagnóstico molecular extremamente difícil, através da análise de DN A, em pacientes isolados. Portanto, hoje o diagnóstico diferencial desta forma de distrofia baseia-se no estudo da proteína disferlina em biópsias musculares.

3) LGM D2G, mapeada em 17q (M oreira et al., 1997). Esta forma de distrofia foi mapeada em uma família brasileira. 0 quadro clínico é bastante variável, com a idade de início variando de 9 a 15 anos, e aumento da enzima sérica CK de 10 a 30 vezes acima do normal. Os afetados apresentam uma fraqueza importante na musculatura proximal e podem ou não ter atrofia distal. Isto é, clinicamente o fenótipo pode ser semelhante à forma LGMD2A ou LGM D2B (Zatz et al., 2000).

Recentemente o produto gênico foi identificado também no nosso laboratório. Trata-se da proteína sarcomêrica tel otonina cuja função também ainda não é conhecida ( $M$ oreira et al., 1998). 0 gene da telotonina é pequeno (tem só dois exons), e, portanto, é viável em casos suspeitos fazer uma triagem de mutações para confirmação de diagnóstico.

\section{Diagnóstico diferencial entre distrofias tipo cinturas e atrofia espinhal progressiva (AEP)}

As atrofias espinhais progressivas (AEP), de herança autossômica recessiva, constituem a forma mais comum de doença do neurônio motor em crianças e jovens adultos. Sua incidência é de cerca de 1/10.000 e a freqüência de heterozigotos de cerca de $1 / 50$. As AEPs são classificadas em três grupos: tipo I ou Werdnig-H offmann (WH), que éa mais severa; tipo II ou forma intermediária; tipo III ou Kugelberg-W elander (KW) que é a menos grave. As três formas são condicionadas por um mesmo gene, SM N 1 (survival motor neuron). 0 gene SM N 1 e uma cópia quase idêntica (SM N2) estão localizados em $5 p 13$ e codificam proteínas idênticas. Entretanto a cópia SM N 2 sofre um processamento alternativo do exon 7 levando a produção de uma proteína truncada. A maioria dos pacientes tem del eções (nos exons 7 e ou 7/8) do gene SM N 1 e aparentemente a severidade do fenótipo é modulada pelo número de cópias de SM N2.

0 estudo molecular do gene SM N 1 em 281 pacientes brasileiros com diagnóstico de AEP mostrou a seguinte freqüência de deleç̃os: 34 em $43(\sim 80 \%)$ no grupo I; 51 em 101 ( $50 \%)$ no grupo II; e 23 em 54 (42.6\%) no grupo III. Além disso, a análise de DNA extraído de vilosidades coriônicas em 16 casos encaminhados para o nosso laboratório para diagnóstico prénatal, mostrou que quatro fetos eram portadores de deleção no gene SM N .

Pacientes afetados por DM C e AEP podem ter um quadro clínico muito semelhante, principalmente nas formas adultas. Além disso, a atividade da enzima sérica CK pode apresentar-se aumentada nas AEPs, com valores semeIhantes aos encontrados nas DM C. Na prática, a análise molecular do gene SM $N$ tem se mostrado extremamente importante para confirmação do diagnóstico clínico e diagnóstico diferencial sem necessidade de exames mais invasivos.

\section{Diagnóstico diferencial nas DMPs e Aconselhamento Genético}

Em pacientes isolados, nos quais o estudo de DNA exclui uma distrofinopatia, o estudo de proteínas musculares é fundamental para diferenciar este grupo de distrofias, das formas de herança ligada ao X, para 0 aconsel hamento genético, como exemplificado abaixo:

1) Nas formas AR, pais de crianças afetadas têm um risco de $25 \%$ de vir a ter outro descendente afetado, independentemente do sexo, enquanto nas distrofinopatias ligadas ao $X$ só existe risco para descendentes de sexo masculino.

2) 0 risco para a descendência de irmãs normais de afetados nas formas AR é desprezível (desde que não se casem com consangüíneo) e pode ser de até $50 \%$ na DM D/DM B, independentemente de casamento (se a irmã for portadora da mutação presente no seu irmão).

3) No caso de herança AR, só existe risco 
para aquele casal, enquanto na DMD/DMB, se a mãe do afetado for portadora, o risco para a sua futura prole independe do casamento.

\section{D istrofia fácio-escápulo-humeral (DFSH)}

Essa forma de distrofia, de herança autossômica dominante, caracteriza-se por um envolvimento predominante da musculatura facial e da cintura escapular, com uma grande variabilidade inter e intrafamilial (Van Deutekom, 1996).

Alguns pacientes têm uma forma extremamente leve que pode se limitar a uma fraqueza na face ou na cintura escapular durante a vida toda enquanto outros podem ter início na infância e uma progressão rápida com perda precoce da ambulação. Em média, entretanto, a progressão é muito lenta e a maioria dos pacientes tem uma sobrevida normal.

0 gene da DFSH foi localizado no cromossomo 4, mas o mecanismo molecular ainda não é conhecido. Nos pacientes afetados ocorre uma deleção de seqüências repetidas de 3.3kb. Existe uma correlação entre o tamanho da deleção e a severidade do quadro clínico embora numa mesma família todos os afetados tenham a mesma deleção (Lunt et al., 1995; Wijmenga et al., 1990; 1992).

Pesquisas em famílias brasileiras com FSHD mostraram que: a) cerca de $1 / 3$ dos casos são resultantes de mutações novas; b) a análise de famílias com duas ou mais gerações sugere que a antecipação (agravamento do quadro clínico em gerações subseqüentes) pode ocorrer nesta forma de distrofia; c) os casos mais graves são geralmente resultantes de mutações novas ou de herança materna (Zatz et al., 1995; 1998).

Outro achado intrigante é que, apesar de se tratar de um gene autossômico dominante (e que, portanto, deveria afetar igual mente os dois sexos), observamos que o sexo masculino émais freqüentemente e, em média, mais severamente afetado do que o sexo feminino (Zatz et al., 1998). 0 estudo molecular de pacientes brasileiros mostrou que esta diferença sexual na freqüência de afetados é devida a uma proporção significantemente maior de mulheres portadoras da deleção e que permanecem assintomáticas. Ainda não se tem uma explicação para estes achados, mas compreender por que as muIheres são, em média, menos afetadas do que os homens vai ser muito importante para futu- ros tratamentos.

Apesar do gene responsável pela DFSH ainda não ter sido isolado, o mecanismo molecular proposto para explicar esta miopatia seria uma deleção de um número integral de cópias de uma seqüência de $3.3 \mathrm{~kb}$ "em tandem". Sugere-se que a função do gene FSHD poderia estar alterada (ou "aumentada") devido a um efeito de posição ou à perda das repetições de 3.3kb. N esse sentido, del eções maiores levariam a uma desativação desse gene proximal em uma proporção maior de células. É possível também que o gene estrutural da DFSH produza transcritos alternativos distintos em diferentes tecidos musculares ou de acordo com a idade (Van Deutekom,1996).

Do ponto de vista prático de aconselhamento genético, é importante salientar que enquanto 0 gene não for clonado, a análise do fragmento 4 q35 só é possível: a) em famílias com múltiplos afetados ou b) nos casos isolados, quando for possível confirmar que um fragmento de tamanho reduzido encontrado no probando está ausente nos seus pais. Por outro lado, sabe-se que pacientes afetados têm um risco de $50 \%$ de passar o gene defeituoso para a sua descendência. Entretanto, 0 aconseIhamento genético nas famílias em risco é complexo, pois deve levar-se em conta a possibilidade de antecipação clínica e também a diferença de manifestação de acordo com o sexo do afetado. Isto é, não épossível prever a severidade do quadro clínico em crianças portadoras da mutação. Por este motivo, do ponto de vista ético, a conduta tem sido de não testar crianças assintomáticas em risco enquanto não houver um tratamento preventivo.

\section{Distrofia miotônica de Steinert}

A distrofia miotônica de Steinert (DMS), uma patologia multissistêmica, é a forma mais comum de distrofia muscular do adulto com uma incidência estimada em 1 em cada 8.500 indivíduos. A herança é autossômica dominante e a idade de início pode variar desde o nascimento (distrofia miotônica congênita) até após os 60 anos de idade com quadro clínico extremamente variável. U ma característica importante é a presença de antecipação clínica, isto é, em genealogias com várias gerações observa-se um aparente aumento de severidade (e/ou idade de início mais precoce) em gerações sucessivas. 
De acordo com a idade de início e os sintomas, os afetados são classificados em diferentes subgrupos (H arper \& Dyken, 1972; H arper, 1989), a seguir discriminados:

1) Forma tardia, leve ou senil, com início geralmente após os 50 anos. Os sinais clínicos podem limitar-se a uma catarata, calvície frontal com um mínimo ou sem comprometimento muscular.

2) Forma clássica, com início na adolescência ou na terceira década, caracterizada por fraqueza e atrofia muscular da musculatura esquelética, fenômeno miotônico (dificuldade para relaxar os músculos quando contraídos, particularmente abrir as mãos), calvície frontal precoce principalmente no sexo masculino, atrofia testicular, podendo haver comprometimento intelectual. O s sinais clínicos neste subgrupo são extremamente variáveis, podendo ocorrer diabete e comprometimento da musculatura lisa com envolvimento gastrointestinal e do trato urinário. Complicações cardíacas, particularmente defeitos de condução e arritmias são freqüentes e constituem uma causa importante de óbito. Cerca de $80-85 \%$ dos pacientes com a forma clássica ou precoce têm alterações no eletrocardiograma.

3) Forma severa infantil com início na primeira década com fraqueza facial, retardo mental importante e comprometimento muscular importante.

4) Forma congênita grave com hipotonia grave ao nascimento, dificuldades respiratórias e de deglutição, retardo mental importante e atraso no desenvol vimento motor. É interessante observar que geralmente a hipotonia e a função motora melhoram durante a primeira infância, mas os sintomas clássicos de distrofia miotônica tendem a reaparecer na segunda dé cada.

Existem também casos atípicos onde se observa, na primeira década, somente retardo mental importante sem outros sinais clínicos, indicando, portanto, a importância de se testar este gene em casos onde foram excluídas outras causas de retardo mental.

O mecanismo molecular responsável pela DM S, cujo gene foi mapeado em 19q é uma expansão de um trinucleotídeo (CTG) na região $3^{\prime}$ não-traduzida do gene que codifica uma proteína quinase ou DM -PK (Aslanidis et al., 1992; Brewster et al., 1998; Brook et al., 1992; Buxton et al., 1992; Fu et al., 1992; $\mathrm{H}$ arley et al., 1992a; M ahadevan et al., 1992; Novelli et al., 1993a). Indivíduos normais podem ter de 5 até
37 repetições (CTG) n. Pacientes afetados podem ter de 50 até 8.000 repetições e existe uma correlação entre o tamanho da expansão em DNA de sangue periférico e a severidade do quadro clínico. Este tipo novo de mutação foi denominado mutação dinâmica e hoje se conhecem várias doenças que são causadas por este mecanismo patológico, isto é, por genes dinâmicos (como a Coréia de H untington, as várias formas de ataxias espinocerebelares e a doença de Kennedy entre outras).

Quando o gene se torna instável, existe uma tendência para um aumento da expansão em gerações sucessivas, o que fornece uma explicação biológica para o fenômeno da antecipação (Ashizawa et al., 1992a; 1992b; H arley et al., 1992; Fu et al., 1992).

Esta variabilidade no tamanho das expansões explica as diferenças na severidade clínica observada na DMS, isto é, como uma mutação, em um mesmo loco, pode resultar em fenótipos tão distintos. Entretanto, é importante salientar que a correlação não é linear e, portanto, o tamanho da expansão CTG em sangue periférico não pode ser utilizado como prognóstico da severidade clínica.

Além disso, o estudo de fetos portadores da mutação mostrou uma grande variabilidade no tamanho da expansão em diferentes tecidos que confirma a heterogeneidade somática (Anvret et al., 1993; Ashizawa et al., 1993). Em pacientes afetados, inclusive da população brasileira, observou-se que a expansão é sempre maior no músculo e fibroblastos (Thornton et al., 1994; Passos-Bueno et al., 1995; Zatz et al., 1995b; 1996) do que no sangue. Entretanto, os mecanismos que levariam a uma expansão tecido-específica diferencial não são conhecidos. Além disso, não observamos, principalmente em adultos, uma correlação entre o tamanho da expansão no músculo e a expansão CTG no sangue ou com a severidade do quadro clínico. O bservou-se também que existe uma expansão (CTG) n contínua com a idade ( $M$ artorel et al., 1995), mas ainda não se sabe se esta explicaria o porquê da progressão da doença. De qual quer modo, esta heterogeneidade do tecido específica explica porque o tamanho da expansão em sangue periférico não pode ser usado como prognóstico clínico.

A partir de experimentos em nível de DNA, RNA e proteína, várias hipóteses foram propostas para explicar os mecanismos patológicos resultantes da expansão CTG tais como: a) a expansão CTG levaria a um efeito de dose 
monogênico, isto é, afetando somente a expressão da DM -PK ; b) a expansão afetaria a expressão de vários genes simultaneamente, isto é, seria uma síndrome causada por genes contíguos; C) a expansão CTG teria efeitos transdominantes em nível de RNA; d) a expansão CTG teria efeitos detrimentais na função celuIar e na replicação celular. Existe, entretanto, muitos resultados conflitantes, já que estudos diferentes em pacientes afetados já descreveram um aumento, uma diminuição ou uma expressão inalterada dos níveis de RN A do gene DM -PK. U ma possível explicação para estes achados disparatados é a grande dificuldade de se comparar pacientes com mesma idade, sexo e grau semel hante de degeneração muscular.

\section{Aspectos genéticos: transmissão e antecipação}

A herança é autossômica dominante na DMS, e mutações novas são raras sugerindo um efeito ancestral fundador. A penetrância, entretanto, não é completa, pois, al guns indivíduos com a mutação podem permanecer assintomáticos ou quase durante toda a vida.

Curiosamente, existe diferença na transmissão de acordo com o sexo (A shizawa et al., 1994a; 1994b; Carey et al., 1994; Chakraborty et al., 1996; Cobo et al., 1993; Gennarelli et al., 1994; Jansen et al., 1994; Lavedan et al., 1993b; Zatz et al., 1997). U ma delas é que a forma congênita grave é transmitida quase que exclusivamente pelo sexo feminino. Por outro lado, existe um excesso significante de afetados do sexo masculino, o que também foi confirmado por nós na população brasileira. Além disso, esta distorção de segregação é mais evidente para descendentes de homens do que mulheres com D MS. A observação de que o al elo mutado é mais freqüentemente transmitido para 0 sexo masculino do que para o feminino fornece uma explicação para o excesso de homens nas famílias de afetados. O utro achado interessante é a baixa incidência da DM S observada por nós na população brasileira de origem africana em comparação com a população cau casóide ou oriental. Esta observação suporta os achados de Goldman et al. (1994) que não identificaram pacientes com DM S na população negróide da África do Sul. De acordo com estes autores, a ausência de D M S nessa população explica-se porque o número máximo de repetições (CTG) n encontrada na população normal foi de 22. Isto é, estaria abaixo do limite de 37 repetições quando aparentemente o gene começa a mostrar-se instável com ten dência a expandir-se.

0 estudo da transmissão do gene da DM em geneal ogias com várias gerações mostrou que em cerca de $80 \%$ dos casos, observa-se antecipação clínica (isto é, o início é mais precoce e o quadro mais severo) acompanhada por um aumento médio da repetição CTG (no sangue periférico) em gerações sucessivas. Além disso, os mai ores aumentos são geralmente transmitidos pela mãe, o que explicaria porque a forma congênita é quase exclusivamente de origem materna.

Por outro lado, já foram descritos exemplos em que o tamanho da expansão no sangue periférico era menor nos descendentes afetados do que na geração parental, isto é, há uma contração da expansão (Abeliovich et al., 1993; Ashizawa et al., 1993; Brunner et al., 1993a). Observou-se também que as contrações ocorrem mais freqüentemente na transmissão de origem paterna (cerca de 10\%) do que de origem materna (cerca de 3\%). Além disso, as maiores expansões paternas têm maior ten dência a se contrair durante a transmissão.

Os dados sugerem que existe um limite no número de repetições CTG em espermatozóides viáveis, isto é, haveria uma sel eção contra espermatozóides com expansões acima de um determinado tamanho (Jansen et al., 1994). Isto explicaria porque descendentes de pais com expansões maiores do que $1.5 \mathrm{~kb}$ tendem a ter expansões menores do que seus pais afetados. Além disso, homens com expansões grandes são freqüentemente estéreis, impedindo, portanto, a transmissão destas para as gerações sucessivas.

\section{H eterogeneidade genética}

Na maioria das famílias (cerca de 98\%) com afetados pela DMS, o estudo molecular confirma tratar-se do gene DM -PK. Entretanto, já foi mapeado um outro gene, em 3q, em uma família com vários afetados e quadro clínico muito semelhante a DM S. Este gene foi classificado como DM 2 (ou DM S2) ou PROM M (Ranum et al., 1998). Embora seu produto ainda não tenha sido identificado, a observação de antecipação clínica sugere tratar-se também de um gene dinâmico, o que acaba de ser confirmado (Ranum et al., 2001, comunicação em congresso).

Portanto, em afetados nos quais não for encontrada expansão (CTG) no gene DM - PK é 
importante suspeitar-se de heterogeneidade genética e testar o gene DM S2/PROM M .

Outras doenças em que ocorre miotonia incluem a miotonia de Thomsen, e a paramiotonia congênita, mas o diagnóstico diferencial é muitas vezes possível por meio de estudos clínicos e/ou pelo modo de herança (Moxley, 1996).

\section{Diagnóstico molecular eAconselhamento G enético}

Em indivíduos clinicamente afetados, o diagnóstico molecular só pode ser confirmado por técnica de Southern blot, pois expansões grandes não são visíveis através de PCR (reação em cadeia da polimerase). $N$ as pessoas em risco (assintomáticas), o diagnóstico molecular pode ser iniciado por técnica de PCR e de acordo com os resultados, confirmado através de técnica de Southern blot. Por exemplo, em indivíduos normais, que são heterozigotos para o número de repetições $C T G$, observam-se duas bandas nítidas através de técnica de PCR. Entretanto, uma única banda pode ser observada tanto em indivíduos normais homozigotos (isto é, onde os dois al elos têm o mesmo número de repetições CTG) como em indivíduos afetados (pois alelos expandidos não são visualizados pela técnica de $P C R$ ).

Portanto, toda vez que for observada uma única banda em um caso suspeito, o resultado precisa ser confirmado por técnica de Southern blot.

0 aconselhamento genético em famílias de afetados é complexo, pois a confirmação do diagnóstico, principalmente em indivíduos assintomáticos ou pouco afetados é dificilmente aceita e o apoio psicológico é muitas vezes necessário. Por outro lado, o diagnóstico precoce é importante para prevenir as complicações cardíacas que são freqüentes nos afetados. Além disso, é importante alertar mulheres portadoras do alelo mutado em relação ao maior risco de ter descendentes com a forma congênita grave.

0 diagnóstico pré natal também é possível através da análise da expansão CTG em DNA extraído de vilosidades coriônicas. Entretanto, não é possível prever qual será a gravidade do quadro clínico em um feto portador da mutação particularmente levando-se em conta a grande heterogeneidade somática no tamanho da expansão.

\section{Perspectivas futuras e aspectos éticos}

\section{0 uso de células-tronco eclonagem terapêutica}

Como acabamos de ver, o estudo do Genoma H umano vai nos ajudar a entender como nossos genes funcionam quando normais e patológicos, como interagem entre si e com o ambiente. Vai ser fundamental para o desenvolvimento de novos tratamentos. A terapia gênica, isto é, a substituição de um gene defeituoso por sua cópia normal, talvez demore um pouco. Entretanto, recentemente, descobriu-se que células ainda não-diferenciadas (stem cells ou células-tronco) presentes, por exemplo, na medula óssea ou no cordão umbilical de um recém-nascido podem manter a capacidade de diferenciar-se em outros tecidos como o muscular ou nervoso. Esta descoberta abre novas esperanças de tratamento para inúmeras doenças hematológicas e degenerativas como as doenças neuromusculares, pois permitirá que células normais de um doador externo (transplante heterólogo) ou que células modificadas do próprio indivíduo doentes (transplante autólogo) sejam capazes de atingir todos os órgãos e tecidos afetados através da corrente sangüínea. Portanto, estabelecer bancos de cordões em vários estados brasileiros é hoje uma prioridade, principalmente considerando-se a sua importância e utilidade já comprovada no caso de doenças hematológicas.

Entretanto, o uso de embriões para obtenção de células-tronco (clonagem terapêutica) tem gerado muitas discussões. As pesquisas com embriões de até 14 dias, para clonagem terapêutica, foram permitidas na Grã Bretanha. É importante salientar que, ao contrário da clonagem reprodutiva, estes embriões nunca serão implantados no útero, mas sim direcionados para fabricar tecidos ou órgãos e não novas vidas humanas.

Sabemos que milhares de embriões, gerados por casais que procuram clínicas de fertilização, são descartados todo ano. Por que não utilizá-los para tentar salvar vidas?

Pesquisas recentes mostram resultados que parecem muito promissores. Um grupo israelense mostrou recentemente (Kehat et al., 2001) que células embrionárias em cultura conseguem transformar-se em células cardíacas, o que abre possibilidades terapêuticas enormes tanto para patologias genéticas como para doenças adquiridas. 
Entretanto, os argumentos contra o uso de embriões para clonagem terapêutica são:

- Pode abrir caminho para clonagem reprodutiva humana

- Pode gerar um comércio de embriões que seriam fabricados apenas para esta finalidade

- Destruir embriões significa destruir vidas

A questão ética que se coloca então é: Quando começa a vida? No momento da fertilização?

Nesse sentido é importante lembrarmos que a chance de que um embrião fertilizado, implantado em um útero materno, se transforme em vida é menor do que $10 \%$. Por outro lado, a chance de que um embrião fertilizado em um laboratório, que não foi implantado, se transforme em vida é ZERO. Não se pode destruir uma vida para salvar outra, dizem os religiosos. M as, se não utilizarmos embriões que são normalmente descartados para tentar salvar vidas, não estaremos destruindo duas vidas?

\section{Testes genéticos e testes preditivos}

\section{Quem deve ser testado?}

U ma das aplicações práticas mais importantes do projeto Genoma Humano, como vimos, é o desenvolvimento de testes genéticos para diagnóstico e para prevenção (a partir da identificação de casais em risco).

O diagnóstico molecular tem sido possível para um número crescente de doenças genéticas o que, em muitos casos, tem sido muito útil, pois permite confirmar o diagnóstico evitando outros exames que podem ser invasivos e pouco informativos. Além disso, a identificação de mutações patogênicas em indivíduos assintomáticos contribui para prevenir o nascimento de novos afetados o que é fundamental para doenças graves ainda incuráveis. Entretanto, como veremos abaixo, existem três situações muito distintas do ponto de vista ético em relação a pessoas, clinicamente normais, que se submetem a testes genéticos.

1) Portadores de mutações que têm risco de vir a ter descendentes afetados, mas que permanecerão assintomáticos durante toda a vida.

2) Portadores de mutações em indivíduos ainda assintomáticos, mas com risco de vir a ser afetados por doenças de manifestação tardia, ainda sem tratamento e, além disso, de transmitir a mutação para seus descendentes.

3) Indivíduos com risco aumentado de vir a ser afetados por doenças de manifestação tar- dia potencialmente tratáveis.

$\mathrm{N}$ a primeira situação, a identificação de casais em risco permite que ele planeje a sua futura prole e evite o nascimento de um afetado. Entretanto, questões éticas, que surgem em situações reais são: Quando oferecer testes? Como evitar os interesses puramente comerciais? Por exemplo, é comum casais de primos, serem encaminhados para um serviço de genética. Se o levantamento da genealogia não revelar a existência de doenças recessivas na família, não há motivo para se realizar testes genéticos porque o risco empírico de $10-12 \%$ não será alterado com a realização desses testes. É importante salientar que quanto mais comum a doença na população (como, por exemplo, a fibrose cística ou a anemia falciforme) menor é a influência relativa da consangüinidade. Realmente em um estudo recente de 227 casais que tiveram filhos afetados por fibrose cística (Bernardino et al., 2000), observamos que $92 \%$ dos casos tinham nascido de pais não-consangüíneos. Além disso, uma criança afetada, filha de primos em primeiro grau, tinha herdado duas mutações diferentes.

Outras questões eticamente importantes são: Até onde vai nosso direito de interferir? Se for descoberto, por acaso, uma falsa paternidade, no caso de um casal que procura o aconseIhamento genético porque teve uma criança afetada, devemos contar? Quando contar? Podemos negar a fazer um teste genético? 0 princípio da confidencialidade, que é uma das regras do aconsel hamento genético, protege quem?

A segunda situação é sempre mais complicada, principal mente no caso de doenças dominantes de manifestação tardia, ainda sem tratamento, como a Coréia de Huntington ou as degenerações espino-cerebelares. N esses casos, os portadores da mutação del etéria, além do risco de $50 \%$ de transmiti-la a sua prole, também serão afetados. Isto é, são testes também preditivos. A pós várias discussões éticas a respeito, o consenso internacional é de não realizar estes testes em crianças assintomáticas para doenças de início tardio, para as quais ainda não há tratamento. Isto porque ao aplicar um teste em uma criança, estamos tirando-Ihe 0 direito de decidir mais tarde se quer ou não ser testada.

Mas, e no caso de adultos, qual é o benefício do teste preditivo? Se o consulente já passou da idade reprodutiva e continua assintomático, por que saber de antemão que será afetado se nada pode ser feito a respeito? É impor- 
tante lembrar que com raras exceções, as pessoas querem ser testadas na expectativa de um resultado negativo, isto é, que o teste revele que não são portadoras da mutação.

Já no caso de jovens, o resultado de um teste pode ser extremamente importante para planejar a sua futura prole e cada caso precisa ser discutido na tentativa de avaliar se o consulente está preparado para um resultado desfavorável.

$\mathrm{N}$ a terceira e última situação, saber que temos predisposição genética (risco aumentado) para doenças potencialmente tratáveis como certos tipos de câncer, hipertensão ou diabete pode ser muito importante para futuros tratamentos. Nesse sentido, uma outra área que promete revolucionar a medicina será a farmacogenética, que estuda por que temos reações tão diferentes a drogas, indo desde uma ausência de resposta até reações tão adversas que podem causar óbito. É o caso, por exemplo, da hipertermia maligna, uma reação violenta a certos anestésicos que causa uma morte rápida se não houver uma intervenção imediata. No futuro próximo, em vez de sermos cobaias cada vez que experimentamos uma medicação nova, os remédios serão receitados de acordo com o perfil genético de cada um.

$M$ as, novamente, a aplicação destes testes abre questões éticas muito importantes. Por exemplo, já foram identificados, dois genes, 0 BRCA1 e o BRCA2, responsáveis pel as formas hereditárias de câncer de mama. M ulheres com mutações em um destes genes têm um risco de 80-90\% de chance de vir a desenvolver câncer e, portanto, o teste é importante para aquelas que tem vários casos na família, principalmente de início precoce. Entretanto, o risco (life time risk) de que qualquer mulher venha a desenvolver câncer de mama durante a vida é de $10 \%$. Portanto, se uma mulher sem história familiar de câncer de mama for testada para os genes BRCA1 eBRCA2 e se nenhuma mutação for detectada, o seu risco de vir a desenvolver câncer de mama continua praticamente o mesmo. A questão ética é: será que as pessoas testadas sabem disso?

Tirar o sangue de uma pessoa pode levar um minuto. Entretanto, devemos sempre lembrar que os resultados de um teste genético não mudam com o tempo e seu impacto pode in- fluenciar o futuro de uma pessoa ou de toda uma família. Por isso, antes de um exame, a pessoa deve ser informada:

1) Para o que está sendo testada?

2) 0 que significa um resultado positivo?

3) 0 que significa um resultado negativo?

4) Qual éa vantagem em ser testado?

5) 0 que pode ser feito a respeito?

Esta discussão pode levar horas, mas ela deve estar acima de qualquer interesse comercial.

\section{Diagnóstico pré-natal e interrupção da gestação}

Casais ou famílias que já tiveram filhos ou parentes afetados por uma doença genética podem, por meio de testes genéticos, saber se correm o risco de vir a ter outros descendentes com o mesmo problema e planejar a sua futura prole. Os casais em risco que desejam ter seus próprios filhos podem se submeter ao diagnóstico pré-natal (DPN). Este permite diagnosticar ao redor da décima semana de gestação se o feto herdou o gene mutado. Ao contrário do que se imagina, a nossa experiência tem mostrado que o DPN de certeza tem sal vado muitas vidas normais no caso de casais que optariam por interromper uma gestação no caso de dúvida. Por outro lado, se for descoberto que o feto é portador de uma mutação responsável por uma doença grave e irreversível, incompatível com uma vida normal, é justo condená-la a nascer para uma vida de sofrimento? Devemos nos conformar ou batalhar para que a nossa legislação acompanhe os avanços científicos? I sto é, que apóie a interrupção médica da gestação em casos de fetos com doenças genéticas graves e irreversíveis, desde que este seja o desejo dos pais?

Em resumo, devemos sempre lembrar que os resultados de um teste genético não mudam com o tempo e seu impacto pode influenciar 0 futuro de uma pessoa ou de toda uma família. Por isso, estes e outras questões éticas devem ser discutidas com toda a sociedade.

1) Quem deve regular a produção de testes genéticos, a sua qualidade e 0 acesso à população?

2) Quem deve ser responsável pela interpretação dos resultados e pelo aconselhamento genético?

3) Q uando oferecer testes?

4) Quem vai controlar a confidencialidade dos resultados? Empregadores e companhias de seguro-saúde terão acesso às informações? 


\section{Agradecimentos}

Gostaríamos de expressar nossos profundos agradecimentos, pela inestimável colaboração, convívio e companheirismo de muitos anos, às seguintes pessoas: dra. Mariz Vainzof, dra. M aria Rita Passos-Bueno, dra. Rita de Cássia Pavanello, dr. Ivo Pavanello, Antônia Cerqueira, $\mathrm{M}$ arta Canovas e Constancia U rbani. Este trabalho foi financiado pela FAPESP, CN Pq e PRONEX.

\section{Referências bibliográficas}

Abe K et al. 1994. Involvement of central nervous system in myotonic dystrophy. J. N eurol. Sci. 127:179-185.

A beliovich B et al. 1993. N egative expansion of the myotonic dystrophy unstable sequence. Am. J. H um. Genet. 52:1.175-1.181.

Anderson LVB et al. 1998. Characterization of monoclonal antibodies to calpain 3 and protein expression in muscle from patients with limb-girdle musclar dystrophy type 2A. Am. J. Pathol. 153:1.169-1.179.

Anderson LVB et al. 1999. Dysferlin is a plasma membrane protein and is expressed early in human development. Hum. M olec. Genet. 8:855-861.

Anvret $M$ et al. 1993. Larger expansions of the CTG repeat in muscle compared to lymphocytes from patients with myotonic dystrophy. H um. M ol. Genet. 2:1.397-1.400.

Ashizawa T et al. 1992a. Anticipation in myotonic dystrophy I. Statistical verification based on clinical and haplotype findings. N eurology 42:1.871-1.877.

Ashizawa T et al. 1992b. Anticipation in myotonic dystrophy II. Complex relationships between clinical findings ans structure of the GCT repeat. N eurology 42:1.877-1.883

Ashizawa T Dubel, JR \& H arati Y 1993. Somatic instability of CTG repeat in myotonic dystrophy. N eurology 43:2.674-2.678.

Ashizawa T et al. 1994a. Characteristics of intergenerational contractions of the CTG repeat in myotonic dystrophy. Am. J. H um. Genet. 54:414-423.

Ashizawa T et al. 1994b. Effects of the sex of myotonic dystrophy patients on the unstable triplet repeat in their affected offspring. N eurology 44:120-122.

Aslanidis C et al. 1992. Cloning of the essential myotonic dystrophy region and mapping of the putative defect. N ature 355:548-551.

Azibi K et al. 1993. Severe childhoood autosomal recessive muscular dystrophy with the deficiency of the $50 \mathrm{kD}$ a dystrophin-associated glycoprotein maps to chromosome 13q12. Hum. M ol. Genet. 2:1.423-1.428.

Baghdiguian S et al. 1999. Calpain 3 deficiency is associated with myonuclear apoptosis and profound perturbation of the IKBa/NF-KB pathway in limb-girdle musculardystrophy type 2. Nature M edicine 5:503511

Bashir R et al. 1998. A novel mammalian gene related to the $C$. el egans spermatogenesis factor fer- 1 is mutated in patients with limb-girdle muscular dystrophy type 2B (LGM D2B). Nature Genet. 20:37-42.
Beckmann JS et al 1991. A gene for limb-girdle muscular dystrophy maps to chromosome 15 by linkage. C. R. Acad. Sci. Paris, t. 312, série III:141-148.

Ben $O$ et al. 1992. Linkage of Tunisian autosomal recessive Duchenne-like muscular dystrophy to the pericentromeric region of chromosome 13q. Nature Genet. 2:315-317.

Bernardino ALF et al. 2000. M olecular analysis in Brazilian cystic fibrosis patients reveals five novel mutations. Genetic testing 4:69-74.

Bonnemann et al. (1995) b-sarcoglycan (A3b) mutations cause autosomal recessive muscular dystrophy with loss of the sarcoglycan complex. N ature Genet. 11: 266-273.

Brewster B, Groenen P \& Wieringa B 1998. M yotonic dystrophy: clinical and molecular aspects. In Emery AEH (ed.). N euromuscular disorders: clinical and molecular genetics. John Wiley $\&$ Sons, N ova York.

Brook JD et al 1992. M olecular basis of myotonic dystrophy: expansion of a trinucleotide (CTG) repeat at the 3 'end of transcript encoding a protein kinase family member. Cell 68: 799-808.

Brunner HG et al. 1993a. Influence of sex of the transmitting parent as well as of parental allele size on the CTG expansion in myotonic dystrophy (DM ). Am. J. H um. Genet. 53:1.016-1.023.

Bushby K 1999. M aking sense of the limb-girdle muscular dystrophies. Brain 122:1.403-1.420.

Buxton J et al. 1992. Detection of an unstable fragment of DNA specific to individuals with myotonic dystrophy. N ature 355:547-548.

Carey N et al. 1994. M eiotic drive at the myotonic dystrophy locus? N ature Genet. 6:17-18.

Chakraborty R et al. 1996. Segregation distortion of the CTG repeats at the myotonic dystrophy locus. Am. J. H um. Genet., 39:109-118.

Cobo AM et al. 1993. Sex-related difference in intergenerational expansion of myotonic dystrophy gene. Lancet 341:1.159-1.160.

Emery AEH 1993. Duchenne muscular dystrophy (2nd ed.). Oxford University Press, Oxford e N ova York, pp. 25-45.

Ervasti JM \& Campbell KP 1991. M embrane organization of the dystrophin-glycoprotein complex. Cell 66:1-20.

Fu YH et al. 1992. An unstable triplet repeat in a gene related to myotonic muscular dystrophy. Science, 255 : 1.256-1.258. 
Gennarelli M, Dallpaiccola B, Baiget $M$, M artorell L \& Novelli $G$ 1994. M eiotic drive at the myotonic dystrophy locus. J. M ed. Genet. 31:980.

Goldman A, Ramsay M \& Jenkins, T 1994. Absence of myotonic dystrophy in southern African N egroids is associated with a significantly lower number of CTG trinucleotide repeats. J. M ed. Genet. 31:37-40.

Harley H G et al. 1992a. Expansion of an unstable DNA region and phenotypic variation in myotonic dystrophy. Nature 355: 545-546.

H arper PS \& Dyken PR 1972. Early onset dystrophia myotonica - evidence supporting a maternal environmental factor. Lancet 2:53-55.

Harper PS 1989. M yotonic dystrophy ( $2^{\text {nd }}$ ed.). W.B. Saunders Co., Londres, Filadélfia, Toronto, Sidney, Tóquio.

Harper PS, Harley HG, Reardon W. \& Shaw DJ 1992. Anticipation in myotonic dystrophy: new light on an old problem. Am. J. H um. Genet. 51:10-16.

H offman EP, Brown RH \& Kunkel LH 1987. Dystrophin: the protein product of the Duchenne muscular dystrophy locus. Cell 51:919-928.

H offman EP et al. 1988. Characterization of dystrophin in muscle-biopsy specimens from patients with Duchenne's or Becker's muscular dystrophy. N. Engl. J. M ed. 318:1.363-1.368.

I keuchi T et al. 1996. Non-M endelian transmission in dentatorubral-pallidoluysian atrophy and $M$ achadoJoseph disease: the mutant allele is preferentially transmitted in male meiosis. Am. J. H um. Genet. 58: 730-733.

Iughetti P, Zatz M , Passos-Bueno M R \& M arie SK 1996. Different origin of mutations for the MachadoJoseph Locus (MJD 1). J. M ed. Genet. 33:439-440.

Jansen $\mathrm{G}$ et al. 1994. Gonosoal mosaicism in myotonic dystrophy patients: involvement of mitotic events in $(\mathrm{CTG})_{n}$ repeat variation and selection against extreme expansion in sperm. Am. J. Hum. Genet. 5:575-585.

Kehat I et al. 2001. Human embryonic stem cells can differentiate into myocytes with structural and functional properties of cardiomyocytes. J. Clin. Invest. 108(3):407-414.

Koenig $\mathrm{M}$ et al. 1987. Complete cloning of the Duchenne muscular dystrophy (DMD) CDNA and preliminary genomic organization of the DM D gene in normal and affected individuals. Cell 50:509-517.

Koenig M, Beggs AH, M oyer M \& Scherpf S 1989. The molecular basis for Duchenne versus Becker muscuIar dystrophy: Correlation of severity with type of deletion. Am. J. Hum. Genet. 45:498-506.

Lavedan C et al. 1993b. M yotonic dystrophy: size and sex-dependent dynamics of CTG meiotic instabiliy and somatic mosaicism. Am. J. H um. Genet. 52: 875883.

Lim LE et al. 1995. b-sarcoglycan (43 DAG): characterization and involvement in a recesssive form of limbgirdle muscular dystrophy linked to chromosome 4q12. N ature Genet., 11:257-265.

Lindlöf M et al. 1989. Gene deletions in X-linked muscular dystrophy. Am. J. Hum. Genet. 44: 496-503.

Liu J et al. 1998. Dysferlin, a novel skeletal muscle gene, is mutated in Miyoshi myopathy and limb-girdle muscular dystrophy. Nat. Genet. 20: 31-36.

Lunt PW et al. 1995. Correlation between fragment size at D 4f104S and age at onset or at wheelchair use with a possible generational effect accounts for much phenotypic variation in 4q35-facioscapulohumeral muscular dystrophy (FSHD). Hum. M olec. Genet. 4:951-958.

M ahadevan M . et al. 1992. M yotonic dystrophy mutation: an unstable CTG repeat in the 3'untranslated region of the gene. Science, 255:1.253-1.255.

Martorell L et al. 1995. Comparison of CTG repeat length expansion and clinical progression of myotonic dystrophy over a five year period. J. M ed. Genet. 32:593-596.

$M$ cNally $E$ et al. 1996. Mild and severe muscular dystrophy caused by a single g-sarcoglycan mutation. Am. J. Hum. Genet. 59:1.040-1.047.

M onaco A, Bertelson C, Liechti-Gallati SH M \& Kunkel LM 1988. An explanation for the phenotipic differences between patients bearing partial deletions of the DM D locus. Genomics 2:90-95.

M oreira ES, Vainzof $M, M$ arie SK, Sertié A, Zatz M \& Passos-Bueno M R 1997. The seventh form of autosomal recessive limb-girdle muscular dystrophy (LGMD2G) is mapped at 17q11-12. Am. J. Hum. Genet 61:151-159.

M oreira ES, Vainzof $M, M$ arie SK, Nigro V, Zatz M \& Passos-Bueno MR 1998. A first missense mutation in the d-sarcoglycan gene associated with a severe phenotype and frequency of limb-girdle muscular dystrophy type $2 F$ (LGMD2F) among Brazilian sarcoglycanopathies. J. M ed. Genet. 35:951-953.

M oreira ES et al. 2000. Limb-girdle muscular dystrophy type $2 \mathrm{G}$ ( LGM 2 2G) is caused by mutations in the gene encoding the sarcomeric protein telethonin. N ature Genet. 24:163-166.

M oxley RT 1996. Proximal myotonic myopathy: mini re view of a recently delineated clinical disorder. $\mathrm{Neu}$ romusc. Disord., 6:87-93.

Neuromuscular Disorders 10 (2001): I-VIII.

Nigro $V$ et al. (1996) The $5 q$ autosomal recessive limbgirdle muscular dystrophy (LGM D2F) is caused by a mutation in the d-sarcoglycan gene. $N$ at. Genet. 14: 195-196.

Novelli G et al. 1993a. (CTG) triplet mutation and phe notype manifestations in myotonic dystrophy patients. Biochem. M ed. M etab. Biol., 50:85-92.

Passos-Bueno MR, Lima MABO \& Zatz M 1990. Estimate of germinal mosaicism in Duchenne muscular dystrophy. J. M ed. Genet. 27:727-728.

Passos-Bueno M R et al. 1992. M osaicism for Duchenne muscular dystrophy mutations: new recurrence risk estimates based on the deletion site in the gene. Am. J. H uman. Genet. 51:1.150-1.155.

Passos-Bueno M R, Vainzof M, M arie SK \& Zatz M 1994. $\mathrm{H}$ alf the dystrophin gene is apparently enough for a mild clinical course: confirmation of its potential use for gene therapy. H um. M olec. Genet. 3:919-922.

Passos-Bueno M R, Cerqueira A, Vainzof M, M arie SK \& Zatz M 1995. M yotonic dystrophy: genetic, clinical and molecular analysis of patients from 41 Brazilian families. J. M ed. Genet. 32:14-19.

Passos-Bueno M R et al. 1996. M ain clinical features for the three mapped autosomal recessive limb-girdle muscular dystrophies and estimated pr d Brazilian families with a relatively mild form of autosomal recessive limb-girdle muscular oportion of each form in 13 Brazilian families. J. M ed. Genet. 33: 97-102. 
Passos-Bueno M R et al. 1995. A common missense mutation in three unrelate dystrophy. Hum. Molec. Genet. 4:1.163-1.167.

Passos-Bueno M R, M oreira ES, Vainzof M , M arie SK \& Zatz M 1996. Linkage analysis in autosomal recessive muscular dystrophy (AR LGMD) maps a sixth form to 5q33-34 (LGM D2F) and indicates that there is at least one more subtype of ARLGMD. Hum. M olec. Genet 5: 815-820.

Passos-Bueno M R, Vainzof M, M oreira ES \& Zatz M 1999. The seven autosomal recessive limb-girdle muscular dystrophies (LGMD): from Igmd2a to Igmd2g. Am. J. M ed. Genet. 82:392-398.

Ranum LPW, Rasmussen PF, Benzow KA, Koob MD \& Day JW 1998. Genetic mapping of a second myotonic dystrophy locus. N ature Genet. 19:196-198.

Rapaport D 1991. Apparent association of mental retardation and specific patterns of deletions screened with probes cf56a e cf23a in Duchenne muscular dystrophy. Am. J. M ed. Genet. 39: 437-441.

Rapaport $D$ et al. 1992. A deletion including the brain promoter of the Duchenne muscular dystrophy gene is not associated with mental retardation. N euromuscular Disorders 2:117-120.

Richard I et al. 1995. M utations in the proteolytic enzyme cal pain 3 cause limb-girdle muscular dystrophy type 2A. Cell 81:27-40.

Richard I et al. 1999. Calpainopathy-a survey of mutations and polymorphisms. Am. J. H um. Genet. 64: 1.524-1.540.

Roberds SL et al. 1994. M issense mutations in the adhalin gene linked to autosomal recessive muscular dystrophy. Cell 78:625-633.

Spencer MJ et al 1997. Absence of calpain 3 in a form of limb-girdle muscular dystrophy (LGM D2A). J. N eurol. Sci. 146: 173-178.

Takata R. Estudos de deleções moleculares com sondas de CDNA ao longo do gene da distrofina. M emória de M estrado, Universidade de São Paulo, São Paulo, 1995.

Thornton, CA, Johnson K \& M oxley, RT 1994. M yotonic dystrophy patients have larger CTG expansions in skeletal muscle than in leukocytes. Ann. Neurol. 35:104-107.

Vainzof $M$ et al 1990. Dystrophin immunostaining in muscles from patients with different types of muscuIar dystrophy: a Brazilian study. J. N eurol. Sci. 98: 221-233.

Vainzof M, Passos-Bueno MR, Takata RI, Pavanello RCM \& Zatz M 1993a. Intrafamilial variability in dystrophin abundance correlated with difference in the severity of the phenotype. J. N eurol. Sci.119:38.

Vainzof M, Passos-Bueno MR, Takata RI, Pavanello RCM \& Zatz M 1993b. Is the maintainance of the Cterminus domain of dystrophin enough to ensure a milder Becker muscular dystrophy phenotype? $\mathrm{H} \mathrm{um}$. Mol. Genet. 2(1):39-42.

Vainzof M et al 1996. The sarcoglycan complex in the six autosomal recessive limb-girdle muscular dystrophies. Hum. M olec. Genet. 5 (12):1.963-1.970.

Vainzof M et al 1999a. Sarcoglycanopathies are responsible for $68 \%$ of severe autosomal recessive limb-girdle muscular dystrophy in the Brazilian population. J. N eurol. Scienc. 164:44-49.

Vainzof M et al. 1999b. Further evidences for the organi- zation of the four sarcoglycans proteins within the dystrophin-glycoprotein complex. European Journal of H uman Genetics 7(2):251-254.

Van Deutekom, JCT 1996. Ph.D. Thesis, University of Leiden, Leiden, Holanda.

Weiler T et al. 1998. A gene for autosomal recessive limbgirdle muscular dystrophy in $\mathrm{M}$ anitoba $\mathrm{H}$ utterites maps to chromosome region 9q31-33: evidence for another limb-girdle muscular dystrophy locus. Am. J. Hum. Genet. 63:140-147.

Wijmenga $C$ et al. 1990. Location of fascioscapulohumeral muscular dystrophy gene on chromosome 4. Lancet 336:651-653.

Wijmenga $C$ et al 1992. Chromosome 4q DNA rearrangements associated with fascioscapulohumeral muscular dystrophy. $\mathrm{N}$ ature $\mathrm{G}$ enet. 2:26-30.

Zatz M, Passos-Bueno M R \& Rapaport D 1989. Estimate of the proportion of Duchenne muscular dystrophy with autosomal inheritance. Am. J. M ed. Genet. 32: 407-410.

Zatz M , Frota-Pessoa O, Levy JA \& Peres CA 1976. Creatine-phosphokinase (CPK) activity in relatives of patients with $\mathrm{X}$-linked muscular dystrophies: a Brazilian study. J. Genet. H um. 24(2):153-168.

Zatz M, Lange K \& Spence MA 1977. Frequency of Duchenne muscular dystrophy carriers. Lancet I, 759.

Zatz M , Vianna-M organte AM , Campos P \& Diament AJ 1981. Translocation $(X ; 6)$ in a female with Duchenne muscular dystrophy: implications for the localisation of the DMD locus. J. Med. Genet.18(6):442-447.

Zatz M et al. 1995a. High proportion of new mutations and possible anticipation following genetic molecular studies in Brazilian facioscapulohumeral muscular dystrophy (FSHD) families. Am. J. Hum. Genet. 56:99-105.

Zatz M et al. 1995b. Analysis of CTG repeat in skeletal muscle of myotonic dystrophy young and adult patients: when does the expansion occur? $\mathrm{H}$ um. M olec. Genet. 4: 401-406.

Zatz M , Passos-Bueno M R, Cerqueira A \& Vainzof M 1996. CTG repeat length in muscle from patients with myotonic dystrophy. J. M ed. Genet. 33:173-176.

Zatz M , Cerqueira A, Vainzof M \& Passos-Bueno M R 1997. Segregation distortion of the CTG repeats at the myotonic dystrophy (DM) locus: new data from Brazilian DM families. J. M ed. Genet. 34:790-791.

Zatz M et al. 1998. The fascioescapulohumeral muscular dystrophy (FSHD1) gene affects more severely and more frequently males than females. Am. J. M ed. Genet. 77:155-161.

Zatz M , Vainzof M, Passos-Bueno M R 2000. Limb-girdle muscular dystrophy: one gene with different phenotypes; one phenotype with different genes. Current O pinion in N eurology 13:511-517.

Zatz M, Vainzof M, Passos-Bueno M R 2001. Serum Creatine-Kinase (CK). In Bushby $\mathrm{K} \&$ Anderson $\mathrm{L}$ (eds.). Progressive M uscular Dystrophies in methods in molecular medicine. Human Press, Twota, Nova Jersey, pp. 31-53. 